\title{
MODELOWANIE UKŁADÓW STEROWANIA Z UŻYCIEM POCHODNYCH UŁAMKOWYCH
}

\begin{abstract}
W pracy przedstawiono przegląd niektórych podejść związanych z problematyką pochodnych ułamkowych w ujęciu teorii sterownia. Zaprezentowano popularne w przemyśle algorytmy sterowania $\mathrm{z}$ użyciem pochodnych ułamkowych, wraz $\mathrm{z}$ metodami projektowania. Stosowanie rachunku różniczkowego o niecałkowitym stopniu jest stosunkowo nowym podejściem, lecz zyskującym na zainteresowaniu. Rozważania w ostatnich latach wskazują, że wiele problemów np. termodynamicznych, czy biologicznych może być z powodzeniem rozpatrywanych za pomocą pochodnych ułamkowych. Na rynku dostępne są już narzędzia, które wspomagają proces identyfikacji oraz projektowania regulatorów w oparciu o dane eksperymentalne. Jednym z takich narzędzi jest CRONE, będącym zestawem narzędzi w Matlabie, który zawiera trzy moduły: matematyczny, identyfikacyjny, projektowania systemu sterowania. Umożliwia zaimplementowanie autorskich regulatorów CRONE o różnym stopniu złożoności. Innym z narzędzi jest FOMCON, który również jest zestawem narzędzi w Matlabie i jest oparty na istniejącym wcześniej narzędziu FOTF. FOMCON umożliwia identyfikację systemu oraz zaprojektowanie regulatora $\mathrm{PI}^{\lambda} \mathrm{D}^{\mu}$. Głównym celem artykułu jest zaprezentowanie obecnego stanu wiedzy, omówienie podstawowych narzędzi i pojęć związanych z pochodnymi ułamkowymi oraz ich zastosowaniem w sterowaniu, takimi jak: funkcja gamma postacie pochodnej i całki o stopniu niecałkowitym, transformata Laplace'a i podstawy teorii sterowania.
\end{abstract}

Słowa kluczowe: PID, CRONE, MATLAB, FOMCON, FOTF, Ninteger, Teoria sterowania, Identyfikacja

\section{Wprowadzenie}

Z uwagi na zwiększające się możliwości obliczeniowe oraz potrzebę zwiększania dokładności stosowanych modeli m.in. w termodynamice, akustyce, czy ekonomii, coraz większe zainteresowanie budzi zastosowanie ułamkowego rachunku różniczkowego [3]. Rozważania na temat pochodnych i całek, których stopień nie jest liczbą całkowitą, sięgają samego początku rachunku różniczko-

\footnotetext{
1 Autor do korespondencji: Grzegorz Rafał Dec, Politechnika Rzeszowska, gdecu2@gmail.com
} 
wego. W korespondencji Leibniza oraz L'Hospitala na temat uogólnienia pojęcia pochodnych przeczytać można, że zastosowanie stopnia 1/2, prowadzi do paradoksu, z którego kiedyś mogą wypłynąć użyteczne konsekwencje [2]. Pierwsze aplikacje ułamkowych pochodnych dokonane zostały w XIX wieku przez Abela, który użył ich do rozwiązania problemu tautochrony, czyli krzywej charakteryzującej się tym, że znajdujące się na niej obiekty stoczą się w tym samym czasie, niezależnie od ich wstępnego położenia [1]. Na przełomie XIX i XX w. Oustaloup rozwinął metodę opartą o dyskretyzację równania z pochodnymi ułamkowymi używając definicji Grünwalda [10]. Trigeassou zaimplementował algorytm aproksymacyjny dla obiektu inercyjnego [11]. Malti rozszerzył koncepcję optymalnej metody dla systemów ułamkowych [12]. Poza wspomnianym modelowaniem obiektów, potencjalnymi korzyściami z zastosowania pochodnych ułamkowych jest zwiększenie szybkości odpowiedzi oraz redukcja błędu stanu ustalonego, zwiększenie stabilności układu regulacji oraz zwiększenie odporności. W ciągu kilku ostatnich dekad rozwinięto sporo narzędzi wspomagających projektowanie układów automatycznej regulacji z użyciem pochodnych ułamkowych. Przykładem jest tutaj CRONE, będącym zestawem narzędzi w pakiecie MATLAB oraz Simulink. Jest rozwijany przez francuską grupę o takiej samej nazwie i zawiera m.in. algorytmy identyfikacyjne pracujące na zgromadzonych danych [5]. Popularny algorytm regulatora PID (Proportional-IntegralDerivative) został przedstawiony przez Podlubnego w postaci ułamkowych równań różniczkowych (FOPID - Fractional-Order PID), również opracowano metody strojenia tego regulatora [4]. FOMCON (Fractional-Order Modeling and Control) podobnie jak CRONE jest zestawem narzędzi w pakiecie MATLAB oraz Simulink. Analiza systemu sterowania opiera się o pojęcie transmitancji. Głównymi funkcjonalnościami FOMCON jest identyfikacja systemu oraz ułatwienie procesu projektowania regulatora $\mathrm{PI}^{\lambda} \mathrm{D}^{\mu}$. Dużą zaletą FOMCOM jest dostępność kodu źródłowego, co pozwala na korzystanie z niego na różnych platformach [1, 2, 3, 8]. Należy również dodać, że np. autorzy w pracy [13] zwracają uwagę na brak jasnej interpretacji fizycznej, czy nierespektowanie zasady jednorodności wymiarowej fizycznych zależności w niektórych zastosowaniach pochodnych ułamkowych. Uczulają na często popełniane błędy w teorii obwodów elektrycznych oraz teorii pola elektromagnetycznego. Zwracają również uwagę, że pochodna ułamkowa nie jest jedynie lokalną operacją, więc przy stosowaniu tego narzędzia należy mieć na uwadze szereg obostrzeń.

\section{Pojęcie pochodnej ułamkowej}

\subsection{Funkcja Gamma}

Uogólnianie pojęcia pochodnych należy zacząć od wprowadzenia funkcji specjalnej $\Gamma(\mathrm{p})$, zwaną Gammą Eulera (1). Funkcja ta jest określona na zbiorze liczb z wyłączeniem całkowitych liczb ujemnych [3]. 


$$
\Gamma(\mathrm{p})=\int_{0}^{\infty} \mathrm{e}^{-\mathrm{x}} \mathrm{x}^{\mathrm{p}-1} \mathrm{dx}
$$

Podstawowymi zależnościami funkcji $\Gamma(\mathrm{p})$ są:

1) Jest ciągła dla $p>0$

2) Ma własność: $\Gamma(\mathrm{p}+1)=\mathrm{p} \Gamma(\mathrm{p})$

3) Zachodzą następujące relacje:

$\Gamma(1)=1$,

$\Gamma(\mathrm{n}+1)=\mathrm{n} !$,

$\Gamma(0)=+\infty$

4) Dla $p=-n: \quad \Gamma(p)=(-1)^{n} \infty$

5) Przykładowe wartości funkcji $\Gamma(p)$ :

$$
\begin{aligned}
& \Gamma\left(\frac{1}{2}\right)=\sqrt{\pi}, \\
& \Gamma\left(-\frac{1}{2}\right)=-2 \sqrt{\pi}, \\
& \Gamma\left(\frac{3}{2}\right)=\Gamma\left(1+\frac{1}{2}\right)=\frac{1}{2} \Gamma\left(\frac{1}{2}\right)=\frac{1}{2} \sqrt{\pi},
\end{aligned}
$$

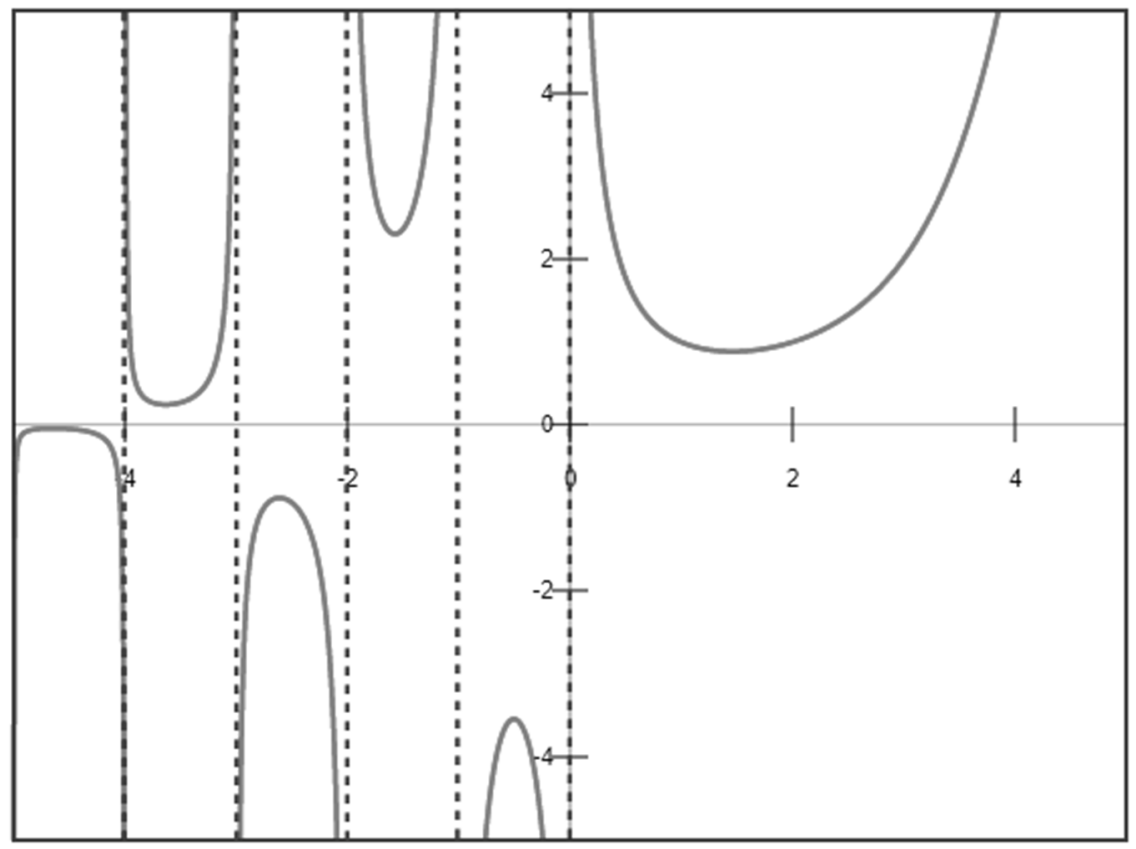

Rys. 1. Wykres funkcji $\Gamma$ (p) (źródło: www.wikipedia.org)

Fig. 1. $\Gamma$ (p) function graph (source: www.wikipedia.org) 


$$
\begin{aligned}
& \Gamma\left(\frac{5}{2}\right)=\Gamma\left(2+\frac{1}{2}\right)=\frac{4 ! \Gamma\left(\frac{1}{2}\right)}{2 ! 2^{4}}=\frac{3}{4} \sqrt{\pi}, \\
& \Gamma\left(\frac{1}{3}\right)=2.678938 \\
& \Gamma\left(\frac{2}{3}\right)=1.354118,
\end{aligned}
$$

6) Zachodzi równość $\frac{\Gamma(p+1)}{\Gamma(q+1) \Gamma(p-q+1)}=\left(\begin{array}{l}p \\ q\end{array}\right)$,

\subsection{Uogólnione pojęcie pochodnej}

Uogólnienie pochodnych powinno posiadać pewne zasadnicze cechy:

1) Jeżeli dowolna funkcja jest k-krotnie różniczkowalna, to istnieje pochodna stopnia $\mathrm{n}<\mathrm{k}$ dla $\mathrm{n}, \mathrm{k} \in \mathrm{R}$,

2) Pochodna stopnia zerowego jest funkcją wyjściową,

3) Istnieje tylko jedna pochodna funkcji k-tego stopnia,

4) Pochodna dowolnej funkcji jest zgodna $z$ wynikiem otrzymanym klasyczną, iteracyjną metodą.

\subsection{Definicja Riemanna-Liouvillea}

W celu wyprowadzenia wykorzystuje się iteracyjną postać całek RiemannaLiouvillea, wychodząc z górnej granicy całkowania zgodnie z (2), a następnie rozważyć podwójną całkę wraz ze zamianą granic całkowania (3) [1].

$$
\begin{aligned}
& f^{(-1)}(x)=\int_{0}^{x} f(k) d k \\
& f^{(-2)}(x)=\int_{0}^{x} \int_{0}^{k} f(t) d t d k=\int_{0}^{x} \int_{t}^{x} f(t) d k d t= \\
& =\int_{0}^{x} f(t) \int_{t}^{x} d k d t=\int_{0}^{x} f(k)(x-t) d t
\end{aligned}
$$

Całkę a-tego stopnia można zapisać jak w (4), zaś pochodną a-tego stopnia jako (5).

$$
\begin{aligned}
& I^{\alpha} f(t)=f^{(-\alpha)}(t)=\frac{1}{\Gamma(\alpha)} \int_{a}^{t} f(u)(t-u)^{\alpha-1} d u \\
& D^{\alpha} f(t)=\frac{1}{\Gamma(n-\alpha)}\left(\frac{d}{d x}\right)^{n} \int_{a}^{t} f(u)(t-u)^{n-\alpha-1} d u
\end{aligned}
$$

gdzie: $n$ jest zaś dodatnią liczbą całkowitą, spełniającą nierówność $n-1<a l f a<n$.

Litera $a$ na początku zapisu oznacza punkt bazowy tj. dolną granicę całkowania. Wyrażenie (4), zwane operatorem całkowym Riemmana-Liouvillea, jest określone jedynie dla $\alpha \geq 0$ oraz $-\infty \leq \mathrm{a}<\mathrm{t}<\infty$. Wyrażenie (5) jest określone dla każ$\operatorname{deg} \alpha$. 


\subsection{Transformata Laplace'a}

W teorii sterowania popularnym podejściem jest analiza systemów regulacji automatycznej na płaszczyźnie S. Płaszczyznę tą można interpretować jako przejście w dziedzinę częstotliwości wraz z uwzględnieniem inercji, tłumienia i tym podobnych zjawisk. Przejścia dokonuje się za pomocą transformacji Laplace'a (6), zaś przejście z powrotem do dziedziny czasu za pomocą transformacji odwrotnej (7), gdzie $i=\sqrt{-1}, \gamma \in \mathrm{R}$.

$$
\begin{aligned}
& F(s)=L[f(t)]=\int_{0}^{\infty} e^{-s t} f(t) d t \\
& f(t)=L^{-1}[F(s)]=\frac{1}{2 \pi i} \lim _{t \rightarrow \infty} \int_{\gamma-i t}^{\gamma+i t} F(s) e^{s t} d t
\end{aligned}
$$

Własności transformaty Laplace'a:

1) Liniowość: $\mathrm{L}[\mathrm{af}(\mathrm{t})+\mathrm{bg}(\mathrm{t})]=\mathrm{aF}(\mathrm{s})+\mathrm{bG}(\mathrm{s}), \quad \mathrm{a}, \mathrm{b} \in \mathrm{R}$,

2) Transformata pochodnej: $L\left[f^{\prime}(t)\right]=s F(s)-f\left(0^{+}\right)$, gdzie $f\left(0^{+}\right) \quad$ oznacza warunek początkowy w punkcie $\mathrm{t}=0$,

3) Transformata całki: $L\left[\int_{0}^{t} f(\tau) d \tau\right]=\frac{1}{s} F(s)$,

4) Opóźnienie, jako przesunięcie w dziedzinie transformaty: $\mathrm{L}[\mathrm{f}(\mathrm{t}-\mathrm{a})]=\mathrm{e}^{-\mathrm{as}} \mathrm{F}(\mathrm{s})$,

5) Splot jednostronny: $\mathrm{L}\left[\left(\mathrm{f}^{*} \mathrm{~g}\right)(\mathrm{t})\right]=\mathrm{F}(\mathrm{s}) \mathrm{G}(\mathrm{s})$,

gdzie: $\quad F(s)=L[f(t)], G(s)=L[g(t)]$,

Transformata Laplace'a dla ułamkowego rachunku różniczkowego znajduje się na (8) i (9).

$$
\begin{aligned}
& I^{a} f(t)=\frac{1}{\Gamma(a)} \int_{0}^{t}(t-y)^{a-1} f(y) d y \\
& L\left[D_{t}^{a} f(t)\right]=s^{a} F(s)-\sum_{k=0}^{n-1} s^{n-a-1}\left[D^{k} I^{n-a} f(t)\right]_{t=0}
\end{aligned}
$$

\subsection{Inne definicje}

W przypadku obliczeń pochodnych ułamkowych z użyciem komputera, często używa się definicji Grünwalda-Letnikova (10), gdzie $h$ oznacza rozmiar kroku obliczeń. Jest ona równoważna definicji Riemanna-Liouvillea [13].

$$
\mathrm{D}_{\mathrm{t}}^{\alpha} \mathrm{f}(\mathrm{t})=\lim _{\mathrm{h} \rightarrow 0} \frac{1}{\mathrm{~h}^{\alpha}} \sum_{\mathrm{k}=0}^{\left[\frac{\mathrm{t}-\mathrm{a}}{\mathrm{h}}\right]}(-1)^{k}\left(\begin{array}{l}
\alpha \\
k
\end{array}\right) \mathrm{f}(\mathrm{t}-\mathrm{kh})
$$

Aproksymując i przyjmując (11) otrzymujemy (12).

$$
D^{\alpha} \mathrm{f}(\mathrm{t}) \approx \Delta_{\mathrm{h}}^{\alpha} \mathrm{f}(\mathrm{t})
$$




$$
\left.\Delta_{h}^{\alpha} f(t)\right|_{t=k h}=h^{-\alpha} \sum_{j=0}^{k}(-1)^{j}\left(\begin{array}{l}
\alpha \\
j
\end{array}\right) f(k h-j h)
$$

Z (12) można wyróżnić (13) jako osobną zmienną, co pozwala zapisać (12) jako (14), które jest już równaniem, które może zostać użyte w obliczeniach numerycznych [1].

$$
\begin{aligned}
& \mathrm{w}_{\mathrm{j}}^{(\alpha)}=(-1)^{\mathrm{j}}\left(\begin{array}{l}
\alpha \\
\mathrm{j}
\end{array}\right) \\
& \left.\Delta_{\mathrm{h}}^{\alpha} \mathrm{f}(\mathrm{t})\right|_{\mathrm{t}=\mathrm{kh}}=\mathrm{h}^{-\alpha} \sum_{\mathrm{j}=0}^{\mathrm{k}} \mathrm{w}_{\mathrm{j}}^{(\alpha)} \mathrm{f}(\mathrm{kh}-\mathrm{jh})
\end{aligned}
$$

Często można spotkać definicję Caputo (15), lecz nie jest w pełni równoważna omówionym wcześniej definicjom. Jest jednak chętnie stosowana przy funkcjach opisanych w dziedzinie czasu, ze względu na łatwe uwzględnienie warunków początkowych [13].

$$
{ }_{a}^{C} D_{x}^{\alpha} f(x)=\frac{1}{\Gamma(n-\alpha)} \int_{a}^{x} \frac{1}{(x-t)^{\alpha-n+1}} \frac{d^{n} f}{d t^{n}} d t
$$

Przy okazji prezentacji innych definicji pochodnej ułamkowej warto zwrócić uwagę na to, że taka pochodna jest zależna od wyboru punktu bazowego a.

\section{Model transmitancyjny}

Modelowanie prostego systemu sterowania opiera się o model transmitancyjny obiektu. Zapis ogólny transmitancji prezentuje (16).

$$
G(s)=\frac{Y(s)}{U(s)}=\frac{b_{m} s^{\beta_{m}}+b_{m-1} s^{\beta_{m}-1}+\ldots+b_{0} s^{\beta_{0}}}{a_{n} s^{\alpha_{n}}+a_{n-1} s^{a_{n-1}+\ldots+a_{0} s^{\alpha_{0}}}}
$$

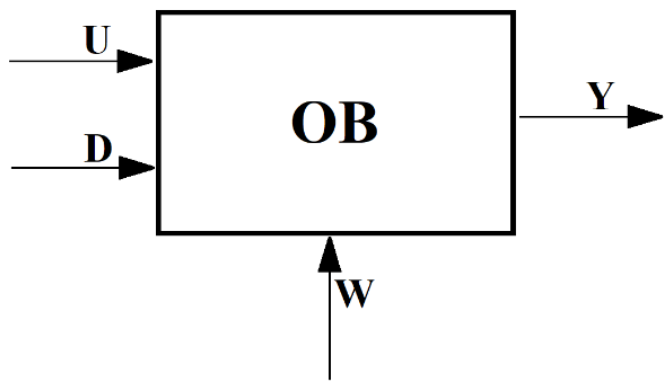

Rys.2. Schemat ogólny obiektu regulacji

Fig.2. Controlled object's structure 
Na rysunku 2 przedstawiono ogólny schemat obiektu regulacji z uwzględnieniem analizowanych sygnałów. W automatyce przyjęto traktować obiekty jako czarną skrzynkę na którą oddziałują pewne sygnały. Zachowanie obiektu można opisać za pomocą transmitancji (16), którą można uzyskać na drodze analitycznej lub na drodze eksperymentów np. poprzez badanie sygnału wyjściowego $\mathbf{Y}$, jako odpowiedzi na skok jednostkowy na wejściu $\mathbf{U}$. Pozostałe sygnały na rysunku 2 to $\mathbf{D}$ - mierzalne zakłócenie oraz $\mathbf{W}$ - niemierzalne zakłócenie. Jednym z podejść identyfikacji transmitancji obiektu dla pochodnych ułamkowych jest zastosowanie definicji Grünwalda-Letnikova, gdzie funkcją celu jest minimalizacja błędu modelu i przebiegu rzeczywistego osiągniętego w trakcie eksperymentu. Ze względu na ograniczenia wynikające np. $\mathrm{z}$ określonej częstotliwości próbkowania odpowiedzi obiektu, należy mieć na uwadze zjawisko aliasingu oraz to, że zmiany szybsze (w dziedzinie częstotliwości) powyżej połowy częstotliwości próbkowania nie zostaną uwzględnione. Podczas obliczeń dobrze jest posłużyć się transmitancją w postaci (17), gdzie wydzielone są zera licznika $Z(p, q)$, pierwiastki mianownika $P(p, q)$ oraz opóźnienie $D(p)$ [1].

$$
\mathrm{G}(\mathrm{s})=\frac{\mathrm{Z}(\mathrm{p}, \mathrm{q})}{\mathrm{P}(\mathrm{p}, \mathrm{q})} \mathrm{D}(\mathrm{p})
$$

Podstawowymi obiektami, które można wyróżnić są:

- inercja pierwszego rzędu (18),

$$
\mathrm{G}(\mathrm{s})=\frac{\mathrm{k}}{\mathrm{Ts}+1}
$$

- integrator (19),

$$
\mathrm{G}(\mathrm{s})=\frac{1}{\mathrm{~T}_{\mathrm{C}} \mathrm{s}}
$$

- integrator z inercją (20),

$$
\mathrm{G}(\mathrm{s})=\frac{\mathrm{k}}{\mathrm{T}_{\mathrm{C}} \mathrm{s}(\mathrm{Ts}+1)}
$$

- podwójny integrator (21),

$$
\mathrm{G}(\mathrm{s})=\frac{k}{s^{2}}
$$

- inercja z opóźnieniem (22),

$$
\mathrm{G}(\mathrm{s})=\frac{\mathrm{k}}{\mathrm{Ts}+1} e^{-\tau s}
$$

- podwójna inercja (23), 
$\mathrm{G}(\mathrm{s})=\frac{\mathrm{k}}{(\mathrm{Ts}+1)^{2}}$

- podwójna inercja z opóźnieniem (24),

$$
\mathrm{G}(\mathrm{s})=\frac{\mathrm{k}}{(\mathrm{Ts}+1)^{2}} e^{-\tau s}
$$

- wielokrotna inercja (25).

$$
\mathrm{G}(\mathrm{s})=\frac{\mathrm{k}}{(\mathrm{Ts}+1)^{n}}
$$

\section{Regulator typu FOPID}

Po wyznaczeniu transmitancji obiektu sterownia można przystąpić do dopasowania regulatora. Jednym $\mathrm{z}$ najpopularniejszych regulatorów spotykanych $\mathrm{w}$ przemyśle jest regulator typu PID. W przypadku pochodnych ułamkowych FOPID, którego pracę opisują równania (26) i (27). Na rysunku 3 znajduje się ogólny schemat układu regulacji automatycznej [14, 15], który można opisać transmitancją względem sygnału sterującego jako (28), zaś transmitancja względem zakłócenia Z (29), będącego superpozycją zakłócenia w i d jako (30).

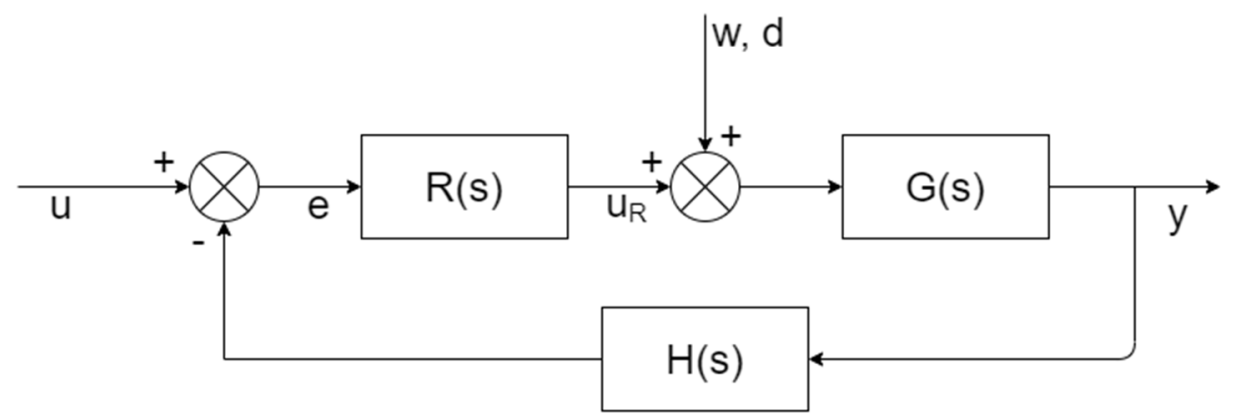

Rys. 3. Schemat ogólny układu regulacji automatycznej

Fig. 3. General schematic of control system

$$
\begin{aligned}
& u_{R}(t)=K_{p} e(t)+K_{i} I^{\lambda} e(t)+K_{d} D_{t}^{\mu} e(t) \\
& R(s)=K_{p}+\frac{K_{i}}{s^{\lambda}}+K_{d} s^{\mu}=\frac{K_{d} s^{(\mu+\lambda)}+K_{p} s^{\lambda}+K_{i}}{s^{\lambda}} \\
& G_{S}(s)=\frac{y}{u}=\frac{R(s) G(s)}{1+R(s) G(s) H(s)} \\
& Z=w+d
\end{aligned}
$$




$$
\mathrm{G}_{\mathrm{Z}}(\mathrm{s})=\frac{\mathrm{y}}{\mathrm{z}}=\frac{\mathrm{G}(\mathrm{s})}{1+\mathrm{R}(\mathrm{s}) \mathrm{G}(\mathrm{s}) \mathrm{H}(\mathrm{s})}
$$

Współczynniki $K_{p}, K_{i}, K_{d}$ określają wzmocnienie dla każdej ze składowej regulatora FOPID tj. odpowiednio części proporcjonalnej, całkującej oraz różniczkowej. Na wejście regulatora podawany jest sygnał błędu $e$, tj. różnicy pomiędzy sygnałem sterującym oraz sygnałem z wyjścia, z uwzględnieniem oddziaływania obwodu sprzężenia zwrotnego $H(s)$. Sygnały $w$ oraz $d$ (jak poprzednio) odpowiadają za zakłócenia niemierzalne oraz mierzalne. Zastosowanie sprzężenia zwrotnego zapewnia odporność na zakłócenia oraz stabilność w punkcie pracy obiektu. Rysunek 4 przedstawia wykres Bodego dla klasycznego regulatora PID. Rysunek 5 dla regulatora FOPID dla $\lambda=\mu=0.75$, zaś rysunek 6 dla $\lambda=\mu=0.5$. W każdym przypadku wzmocnienia każdego $\mathrm{z}$ członów są jednakowe i równe jedności. Jak widać zarówno charakterystyka amplitudowa, jak i fazowa różnią się od siebie dla każdego z przypadków. Wraz ze zmniejszaniem się parametrów $\lambda$ oraz $\mu$ charakterystyki stają się bardziej płaskie. Przesuwa się również punkt zerowy w kierunku częstotliwości mniejszych od 1.

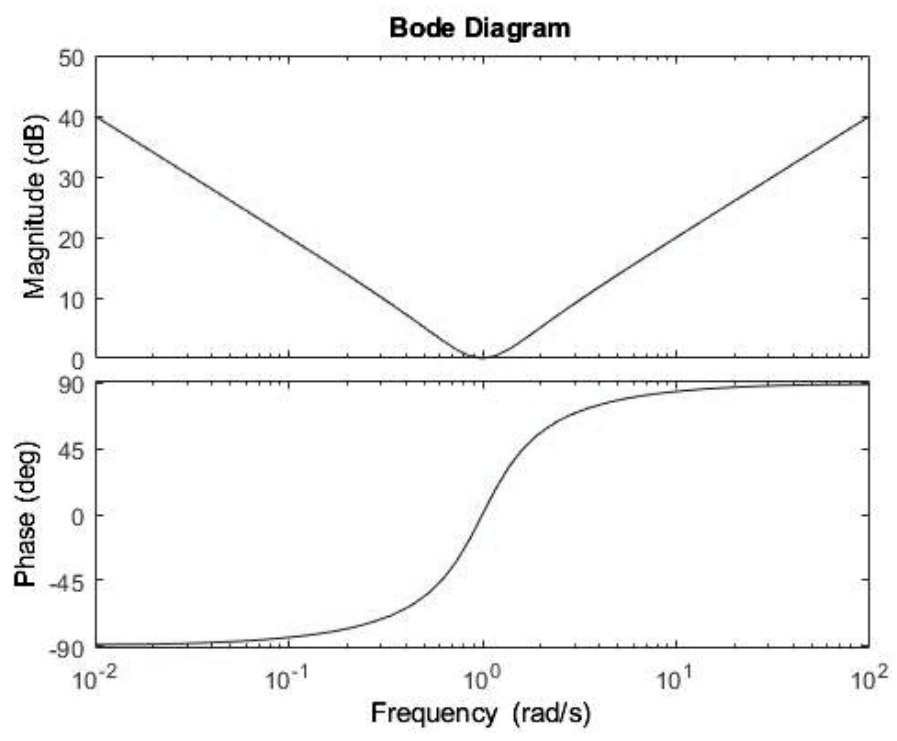

Rys. 4. Wykres Bodego regulatora PID

Fig. 4. Bode plot of PID regulator 

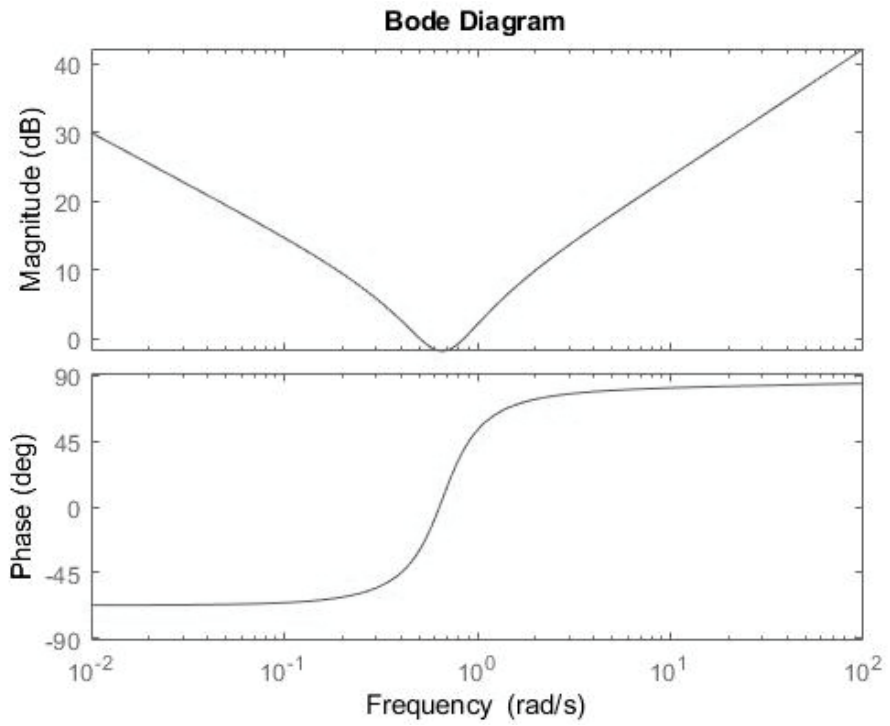

Rys. 5. Wykres Bodego regulatora FOPID dla $\lambda=\mu=0.75$

Fig. 5. Bode plot of FOPID regulator for $\lambda=\mu=0.75$

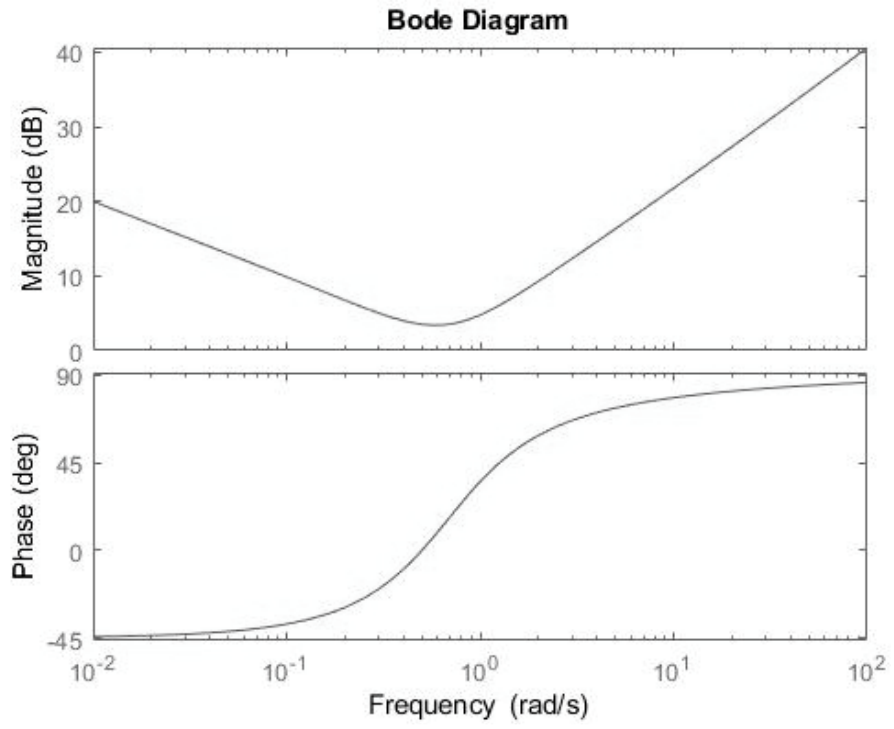

Rys. 6. Wykres Bodego regulatora FOPID dla $\lambda=\mu=0.5$

Fig. 6. Bode plot of FOPID regulator for $\lambda=\mu=0.5$ 
Ze względu na możliwość różnego opisu obiektu oraz regulatora, można wyróżnić 4 sytuacje: model obiektu oraz model regulatora $\mathrm{z}$ pochodnymi całkowitego rzędu; model obiektu z pochodnymi całkowitego rzędu, zaś regulator z pochodnymi ułamkowymi; model obiektu z pochodnymi ułamkowymi, zaś regulator z pochodnymi całkowitoliczbowego rzędu; model obiektu i regulatora opisany pochodnymi ułamkowymi. Z praktycznego punktu widzenia, częściej dokonuje się transferu modelu regulatora do pochodnych ułamkowych niżeli modelu obiektu [1].

\section{Metoda F-MIGO}

Bazując na metodzie Ziglera-Nicholsa, która pozwala na nastrojenie regulatorów PID, na przestrzeni ostatnich lat zaczęto pracę nad metodą F-MIGO (Fractional $\mathrm{M}_{\mathrm{s}}$ constrained Integral Gain Optimization), gdzie starano się optymalizować wzmocnienie części całkującej. Metoda ta jednak jest skierowana do regulatorów typu $\mathrm{PI}^{\lambda}$. Głównymi motywacjami do badań były dwie wady metody Ziglera-Nicholsa: bardzo mała ilość informacji o procesie brana pod uwagę przy doborze parametrów regulatora; dobrane parametry nie zawsze zapewniają wystarczającej w przemyśle niezawodności i odporności na zakłócenia. Ważnym założeniem przy tej metodzie jest to, że dana jest transmitancja obiektu $G(s)$, co pozwala zdefiniować dwie pomocnicze funkcje (31).

$$
\mathrm{S}(\mathrm{s})=\frac{1}{1+\mathrm{R}(\mathrm{s}) \mathrm{G}(\mathrm{s})}, \quad \mathrm{T}(\mathrm{s})=\frac{\mathrm{R}(\mathrm{s}) \mathrm{G}(\mathrm{s})}{1+\mathrm{R}(\mathrm{s}) \mathrm{G}(\mathrm{s})}
$$

Łatwo zauważyć, że $S(s)+T(s)=1$. Funkcja $S(s)$ jest nazywana funkcją czułości układu, zaś $T(s)$ funkcją tłumienia dla zakłóceń. Wartości szczytowe dla obu funkcji określa się za pomocą parametrów $M_{S}$ oraz $M_{P}(32)$.

$$
\mathrm{M}_{\mathrm{S}}=\max _{0<\omega<\infty}|\mathrm{S}(\mathrm{j} \omega)|, \quad \mathrm{M}_{\mathrm{P}}=\max _{0<\omega<\infty}|\mathrm{T}(\mathrm{j} \omega)|
$$

Zauważono, że parametr $M_{S}$ jest dobrym wyborem do optymalizacji, ponieważ zmiany tego parametru znacząco wpływają na odpowiedź impulsową układu. Jednocześnie powinna być utrzymywana małą wartość parametru $M_{P}$. Problem zaś można sprecyzować następująco: „,Maksymalizacja wzmocnienia członu catkujacego tak, by uzyskać stabilność dla zamkniętej pętli sprzężenia zwrotnego oraz wykres Nyquista leży poza okręgiem o środku $s=-C$ (33) oraz promieniu $R$ (34)".

$$
\begin{aligned}
& \mathrm{C}=\frac{\mathrm{M}_{\mathrm{S}}-\mathrm{M}_{\mathrm{S}} \mathrm{M}_{\mathrm{P}}-2 \mathrm{M}_{\mathrm{S}} \mathrm{M}_{\mathrm{P}}{ }^{2}+\mathrm{M}_{\mathrm{P}}{ }^{2}-1}{2 \mathrm{M}_{\mathrm{S}}\left(\mathrm{M}_{\mathrm{S}}{ }^{2}-1\right)} \\
& \mathrm{R}=\frac{\mathrm{M}_{\mathrm{S}}+\mathrm{M}_{\mathrm{P}}-1}{2 \mathrm{M}_{\mathrm{S}}\left(\mathrm{M}_{\mathrm{S}}{ }^{2}-1\right)}
\end{aligned}
$$


Problem ten można sprecyzować jako równania (35) i (36) [1].

$$
\begin{aligned}
& f\left(K_{P}, K_{I}, \omega, \alpha\right)=|1+C(j \omega) G(j \omega)|^{2} \\
& f\left(K_{P}, K_{I}, \omega, \alpha\right) \geq R^{2}
\end{aligned}
$$

Problemem optymalizacyjnym jest zatem znalezienie możliwie największej wartości $K_{I}$ przy spełnieniu warunku (36). Na wykresie Rys. 7 znajduje się przykładowy wykres Nyquista dla $\mathrm{G}(\mathrm{s})=\frac{1}{\mathrm{~s}^{2}-2 \mathrm{~s}+1}$. Wykresy Nyquista tworzy się również w celu badania stabilności systemu zamkniętego sprzężeniem zwrotnym. Układ otwarty jest stabilny, gdy wszystkie bieguny transmitancji G(s) leżą na lewej półpłaszczyźnie zmiennej zespolonej s. Układ zamknięty jest stabilny, gdy jego charakterystyka nie obejmuje punktu $(-1, \mathrm{j} 0)$ - punkt ten określa granicę stabilności systemu. Kryterium stabilności Nyquista pozwala na łatwe określenie zapasu stabilności badanego układu. Zapas stabilności określa się jako zapas modułu (określa krotność wzmocnienia, przy stałym sterowaniu do osiągnięcia granicy stabilności układu zamkniętego) oraz zapas fazy (określa wartość zmiany sterowania przy stałym wzmocnieniu, która doprowadziłaby na granicę stabilności) [15].

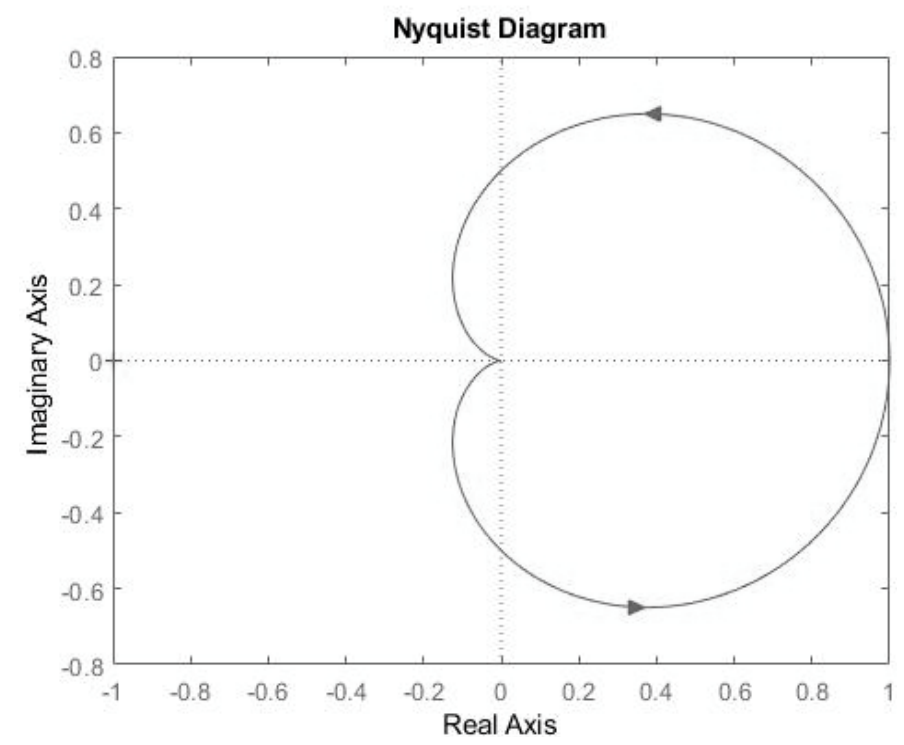

Rys. 7. Przykładowy wykres Nyquista dla $G(s)=\frac{1}{s^{2}-2 s+1}$

Fig. 7. Example of Nyquiste plot, where $G(s)=\frac{1}{s^{2}-2 s+1}$ 


\section{Zestaw narzędzi CRONE}

Bazując na dokonaniach w badaniach Oustaloupa nad zastosowaniem pochodnych ułamkowych $w$ sterowaniu została zaprezentowany zestaw narzędzi CRONE wraz z możliwością stworzenia regulatorów [1, 5]. Istnieją trzy generacje tego typu regulatorów, które cechuje:

- metodologia oparta o opis parametrów w dziedzinie częstotliwości przy użyciu pochodnych ułamkowych,

- zarówno ciągły jak i dyskretny opis systemów SISO oraz MIMO,

- jednostkowe sprzężenie zwrotne,

- brak przeestymowania parametrów - lepsze dopasowanie do obiektu.

Pierwsza generacja regulatorów CRONE jest odpowiednia dla zakłóceń o charakterze proporcjonalnym oraz przy stałej fazie wokół ustalonych parametrów sterowania. Transmitancję opisuje równanie (37).

$$
\mathrm{R}(\mathrm{s})=\mathrm{R}_{0} \mathrm{~s}^{\alpha} ; \quad \alpha, \mathrm{R}_{0} \in \mathrm{R}
$$

Przy stosowaniu tej generacji dobrze jest, by obiekt miał już stałą fazę (w rozumieniu charakterystyk Bodego), przynajmniej w zakresie punktu pracy, określonego dla asymptotycznej odpowiedzi obiektu. W takim przypadku, dzięki pętli sprzężenia zwrotnego, układ będzie odporny na wahania wzmocnienia, nawet w przypadku stosunkowo niewielkiej zmiany punktu pracy. W rzeczywistych warunkach trudno jest dobrać wzmocnienie w otwartej pętli by spełnić wspomniany warunek, wtedy regulator CRONE pierwszej generacji nie jest w stanie zapewnić niezawodności działania. Charakterystyki Bodego dla pierwszej generacji generatora CRONE znajdują się na rys. 8 .

Drugą generację regulatorów CRONE opisuje równanie (38) (transmitancja systemu z otwartą pętlą sprzężenia zwrotnego).

$$
\mathrm{F}(\mathrm{s})=\mathrm{R}(\mathrm{s}) \mathrm{G}(\mathrm{s})=\left(\frac{\omega_{\mathrm{cg}}}{\mathrm{s}}\right)^{\alpha} ; \alpha \in \mathrm{R}, \alpha \in[1,2]
$$

Chcianą charakterystykę otwartej pętli powinno cechować:

- zapas fazy: $\varphi_{\mathrm{m}}=(2-\alpha) \pi / 2$,

- zapas wzmocnienia: $\mathrm{M}_{\mathrm{g}}=\sin \left(\frac{\alpha \pi}{2}\right)$,

- zapas wzmocnienia dla rezonansu: $\mathrm{M}_{\mathrm{r}}=\frac{1}{\sin \left(\frac{\alpha \pi}{2}\right)}$,

- współczynnik tłumienia, zależny od pierwiastków mianownika: $\zeta=-\cos \left(\frac{\pi}{\alpha}\right)$. 


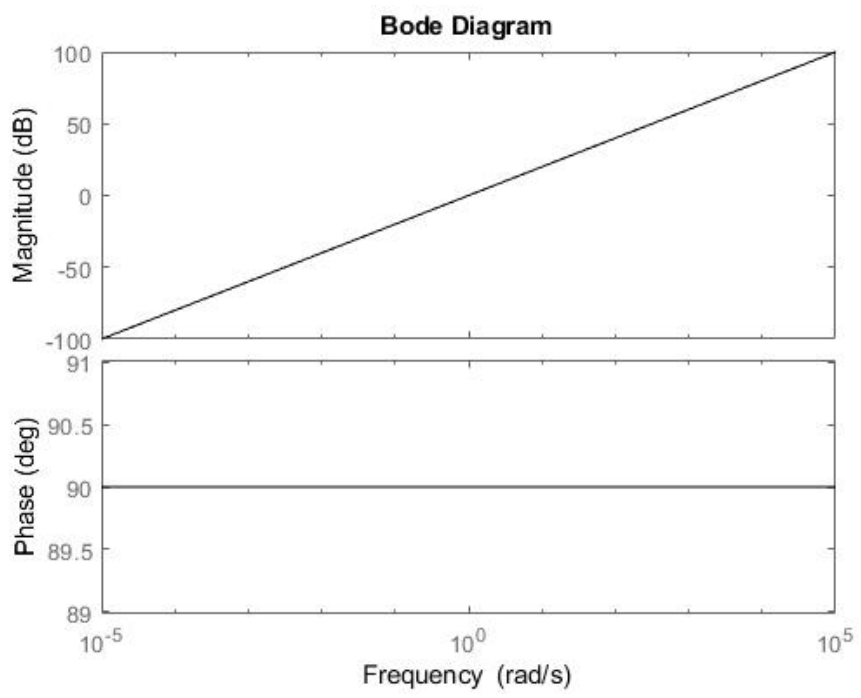

Rys. 8. Wykres Bodego pierwszej generacji regulatora CRONE

Fig. 8. Bode plot of first generation of CRONE regulator

Jedną z metod doboru parametrów regulatora jest posłużeniem się aproksymacją Oustaloupa zgodnie z równaniem (39), wtedy transmitancja regulatora $R(s)$ może być obliczona z (40).

$$
\mathrm{F}_{\mathrm{R}}(\mathrm{s})=\mathrm{k}^{\prime}\left(\frac{\omega_{\mathrm{b}}}{\mathrm{s}}+1\right)^{\mathrm{n}_{\mathrm{b}}}\left(\frac{\omega_{\mathrm{h}}+\mathrm{s}}{\omega_{\mathrm{b}}+\mathrm{s}}\right)^{\mathrm{n}} \frac{1}{\left(\mathrm{~s}+\omega_{\mathrm{h}}\right)^{\mathrm{n}_{\mathrm{F}}}}
$$

gdzie:

$$
\begin{aligned}
& \omega_{\mathrm{b}}, \omega_{\mathrm{h}}, \mathrm{k}^{\prime} \in \mathrm{R}^{+} ; \quad \mathrm{n}_{\mathrm{b}}, \mathrm{n}_{\mathrm{F}} \in \mathrm{N}^{+} \\
& \mathrm{R}(\mathrm{s})=\frac{\mathrm{F}_{\mathrm{R}}(\mathrm{s})}{\mathrm{G}(\mathrm{s})}
\end{aligned}
$$

Regulatory drugiej generacji dobrze jest stosować tam, gdzie faza odpowiedzi obiektu waha się w pewnym otoczeniu punktu pracy. Na rys. 9 można zobaczyć charakterystyki Bodego dla systemu z zamkniętą pętlą sprzężenia zwrotnego oraz drugiej generacji regulatorem CRONE.

Trzecia generacja regulatorów CRONE jest próbą odpowiedzi na potrzeby regulacji w przypadku wahań wzmocnienia i fazy lub błędu w określeniu pierwiastków i zer transmitancji. Jest to przypadek najbardziej odpowiadający rzeczywistości. Działanie opiera się o zapewnienie nieprzekroczenia wartości wzmocnienia w zamkniętej pętli tak by pozostać w obszarze wykresów Nicholsa zapewniających stabilną pracę i odpowiednio wysokie tłumienie zakłóceń tj. jak 


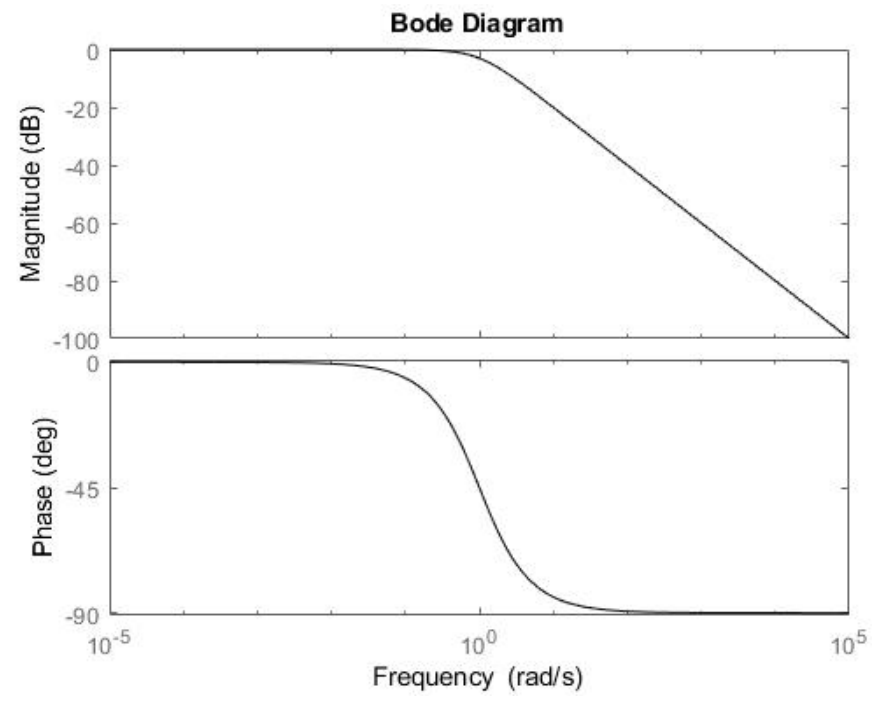

Rys. 9. Wykres Bodego systemu z zamkniętą pętlą sprzężenia zwrotnego $\mathrm{z}$ drugiej generacji regulatorem CRONE

Fig. 9. Bode plot of a system with second generation of CRONE regulator and closed feedback loop

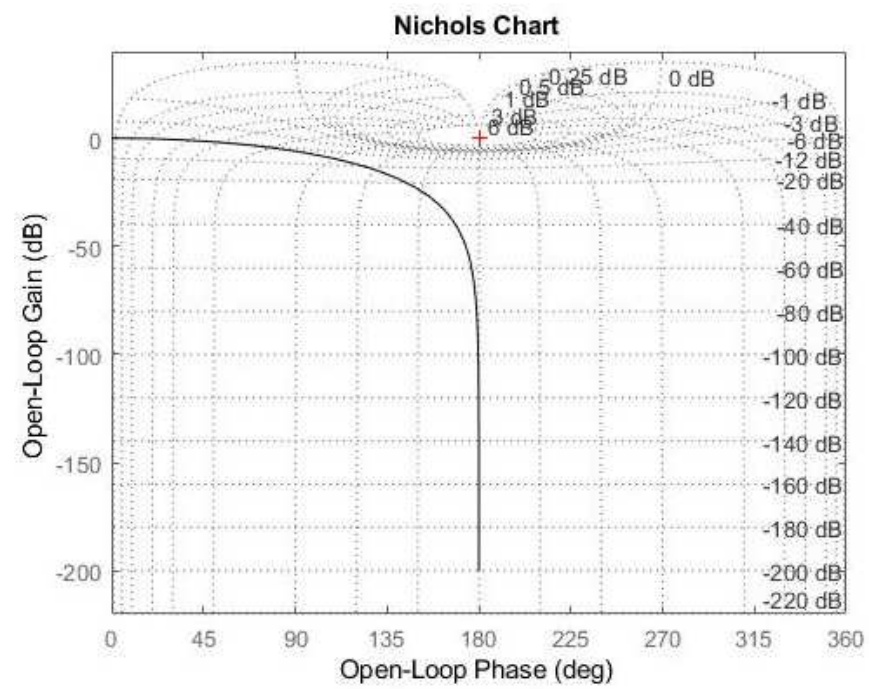

Rys. 10. Charakterystyka Nicholsa dla przykładowej transmitancji: $\mathrm{G}(\mathrm{s})=\frac{1}{\mathrm{~s}^{2}-2 \mathrm{~s}+1}$

Fig. 10. Nichols chart for example of transfer function: $G(s)=\frac{1}{s^{2}-2 s+1}$ 
najdalej od punktu $(0 \mathrm{~dB},(2 \mathrm{k}+1) \pi \mathrm{rad})$, gdzie $\mathrm{k} \in \mathbb{Z}$. Na podstawie wykresów Nicholsa dobiera się parametry zastępczej transmitancji $F(s)$. Same wykresy Nicholsa są analogiczne do charakterystyk Bodego z tą różnicą, że na jednej osi jest faza sygnału, zaś na drugiej wzmocnienie. Na rys. 10 znajduje się siatka izolinii wykresu Nicholsa z przykładową charakterystyką dla $G(s)=\frac{1}{s^{2}-2 s+1}[1,5]$.

\section{FOMCON}

FOMCON jest zestawem narzędzi dla Matlaba wspomagającym pracę z pochodnymi ułamkowymi. Dzięki otwartemu dostępowi do kodu źródłowego jest możliwe korzystanie z niego również na innych platformach obliczeniowych np. Scilab. Został opracowany na bazie FOTF (Fractional-Order Transfer Function). Obliczenia przeprowadzane są w oparciu o transmitancję w postaci (41).

$$
G(s)=\frac{b_{m} s^{\beta_{m}}+b_{m-1} s^{\beta_{m}-1+\ldots+b_{0}} s^{\beta_{0}}}{a_{n} s^{\alpha_{n}}+a_{n-1} s^{\alpha_{n-1}+\ldots+a_{0} s^{\alpha_{0}}}}
$$

Głównymi funkcjonalnościami jest identyfikacja w dziedzinie czasu i częstotliwości (moduł identyfikacyjny) oraz wspomaganie projektowania układów sterowania (moduł sterowania). W ramach modułu sterowania dostępne są narzędzia wspomagające projektowanie regulatora FOPID, określanie granic sterowania, korekcja nastaw regulatora w trakcie jego działania, odporność na wahania parametrów. Implementacja może odbywać się w przypadku analizy ciągłej jak i dyskretnej. FOMCON umożliwia dodanie algorytmów filtrów analogowych.

\section{Wnioski}

Zastosowanie pochodnych ułamkowych jest bardziej odpowiednie dla uzyskania możliwie optymalnego sterowania dla niektórych procesów fizycznych. Wiąże się jednak z bardziej złożonymi obliczeniami oraz większą potrzebną wiedzą na temat obiektu sterowania. W praktyce wybór metody sterowania zależy mocno od ilości dostępnych danych przez co prostsze metody sterowania są chętniej stosowane. Rozbudowa tradycyjnego regulatora PID do FOPID jest możliwa przy niewielkim rozszerzeniu stosowanych metod strojenia. Powstawanie narzędzi takich jak biblioteka CRONE, czy FOMCON dla Matlaba ułatwiają proces identyfikacji i doboru parametrów systemu, przez co jest duża szansa na chętniejsze stosowanie regulatorów opartych o pochodne ułamkowe w przemyśle.

\section{Literatura}

[1] Monje A.C., Chen Y., Vinagre M.B., Xue D., Feliu Vincente., Fractional-order Systems and Controls, Springer, London 2010.

[2] Tepljakov A., Fractional-order Modeling and Control of Dynamic Systems, Springer, London, 2017. 
[3] Milici C., Draganescu G., Machado T. J., Introduction to Fractional Differential Equations, Springer 2019.

[4] Podlubny I., Fractioanl-order Systems and Fractional-order Controllers, OLYMPIA s.r.o., Koszyce 1994.

[5] Malti R., Victor S., CRONE Toolbox for system identification using fractioanl differentiation models, Symposium on System Identification, Beijing, 2015.

[6] Tan N., Yuce A., Deniz N.F., Teaching fractional order control systems using interactive tools, The Eurasia Proceedings of Educational \& Social Sciences, 2016.

[7] Chen Y., Petras I., Xue D., Fractional Order Control - A Tutorial, American Control Conference, St.Louis, 2009.

[8] Dulau M., Gligor A., Dulau T.M., Fractional Order Controllers versus Integer Order Controllers, $10^{\text {th }}$ International Conference Interdisciplinarity in Engineering INTER-ENG, 2016.

[9] Tepljakov A., Fractional-order Calculus based Identification and Control of Linear Dynamic System, Tallinn 2011.

[10] Oustaloup A., Mathieu B., Identification of non integer order system in the timedomain, IEEE-CESA '96 SMC IMACS Multiconference, 1996.

[11] Trigeassou J., Poinot T., Oustaloup A., Levron F., Modelink and identification of a non integer order system, ECC, Karlsruhe, Germany, 1999.

[12] Malti R., Victor S., Oustoulap A., Advances in system identification using fractional models, Journal of Computational and Nonlinear Dynamics, 2008.

[13] Sikora R., Pawłowski S., O pewnych aspektach stosowania pochodnych ułamkowych w elektrodynamice, Przegląd elektrotechniczny R.94 nr 1.2018.

[14] Kaczorek T., Dzieliński A., Dąbrowski W., Łapatka., Podstawy teorii sterowania, WNT, Warszawa, 2013.

[15] Amborski K., Marusak A., Teoria sterowania w ćwiczeniach, PWN, Warszawa, 1978.

[16] Wysocki M., Sterowanie Wielowymiarowe, Oficyna wydawnicza PRz, Rzeszów 2004.

\section{CONTROL SYSTEM MODELING WITH USING FRACTIONAL DERIVATIVES}

\section{S u m m a r y}

In the paper is presented review of some approaches corelated with subject of using fractional derivatives in control system theory. Popular algorithms used in the industry are presented, along with relating designing methodology. Using of fractional derivatives calculations is relatively new concept, but constantly getting increasing interest. Deliberation in recent years indicate that many scientific problems like thermodynamic or biology problems can be well considered and modeled by fractional order derivatives. On the market there is available tools that support a processes of identification and regulators designing, based on experimental data. One of such tools are toolbox 
CRONE for MATLAB, which contains three modules: mathematical, identifying, system control designing. That toolbox allows implementation of CRONE regulators with different level of complexity. Other tool is FOMCON, which also is a toolbox for MATLAB and it is based on already existed toolbox FOTF. FOMCON allows to identifying of control system and $\mathrm{PI}^{\lambda} \mathrm{D}^{\mu}$ regulator designing. This article is aiming to present current state of art, discussion about existing tools and concepts correlated with fractional order derivatives and their usage in control system theory, like: gamma function, definition of fractional derivative, Laplace transform and basics of control system theory.

Kaywords:, PID, CRONE, MATLAB, FOMCON, FOTF, Ninteger, Control system theory, Identifying

DOI: $10.7862 /$ re. 2020.3

Przestano do redakcji: marzec $2020 r$.

Przyjęto do druku: luty $2021 \mathrm{r}$. 